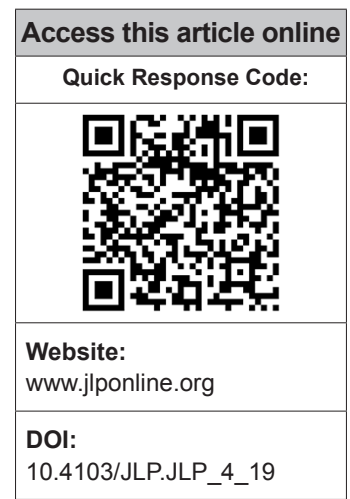

Composite Laboratory, ACTREC-Tata Memorial Centre, ${ }^{1}$ Department of Microbiology, ACTREC-Tata Memorial Centre, ${ }^{2}$ Department of Quality Management, ACTREC-Tata Memorial Centre, Navi Mumbai, Maharashtra, India

Address for correspondence: Dr. Vivek G. Bhat, Department of Microbiology, ACTREC-Tata Memorial Centre, Sector 22, Kharghar, Navi Mumbai - 410 210, Maharashtra, India. E-mail: vbhat@actrec. gov.in

Submission: 10-01-2019 Accepted: 31-05-2019

\title{
Reduction in sample rejections at the preanalytical phase - Impact of training in a tertiary care oncology center
}

\author{
Preeti D. Chavan, Vivek G. Bhat ${ }^{1}$, Pratik P. Poladia, Manikchandra R. Tiwari, \\ Chital Naresh ${ }^{2}$
}

\section{Abstract:}

CONTEXT: Major clinical decisions are based on the laboratory test results where preanalytical errors are an important cause of repeat collections in patients. Identification of problem areas and continuous training of phlebotomy staff are important tools in reducing these errors.

AIMS: In this study, we looked at the most common causes of sample rejection in our setting and the efficacy of the corrective measures and training processes for staff in reducing preanalytical errors.

SETTINGS AND DESIGNS: This prospective study was conducted at the laboratory diagnostic services of a tertiary care oncology center, with a hematopoietic stem cell transplant unit during the period of 2012-2017 in two phases. Sample rejections from various wards were analyzed for types of rejections.

MATERIALS AND METHODS: In the first phase, we analyzed the problem areas (year 2012). Following a root cause analysis, current practices of training were altered. In the second phase (2013-2017), we studied the effects of these measures.

STATISTICAL ANALYSIS USED: The percent variation and $P$ value for significance in sample rejections were calculated.

RESULTS: During the year 2012, 0.36\% samples were rejected by laboratory. Following interventions in the period from 2013 to 2017 , samples rejected dropped to $0.19 \%(P<0.0001), 0.09 \%(P<0.0001)$, $0.09 \%(P=0.8387), 0.05 \%(P=0.0004)$, and $0.05 \%(P=0.329)$, respectively. The reduction was significant from surgical oncology ward $(P=0.0107)$ and intensive care unit $(P=0.0007)$. From 2013 to 2017 , errors significantly reduced to $0.015 \%$ for hemolyzed samples ( $P=0.0001$ ), $0.005 \%$ for contaminated samples, $0.036 \%$ for clotted samples, and $0.019 \%$ for labeling errors.

CONCLUSION: Intervention in the form of targeted training helps reduce errors and improves the quality of results generated and contributes to better clinical outcomes.

Key words:

Intervention, laboratory errors, quality assurance, root-cause analysis, sample rejection, training efficacy

\section{Introduction}

NI ajor clinical decisions are based on the laboratory test results and have a direct bearing on patient care. The accuracy

This is an open access journal, and articles are distributed under the terms of the Creative Commons Attribution-NonCommercial-ShareAlike 4.0 License, which allows others to remix, tweak, and build upon the work non-commercially, as long as appropriate credit is given and the new creations are licensed under the identical terms.

For reprints contact: reprints@medknow.com of laboratory reports has a direct impact on clinical diagnosis, thereby playing an important role in patient management and safety. ${ }^{[1]}$ This, in turn, depends on the quality of the procedures associated with the three main phases of laboratory testing, i.e., the preanalytical, analytical, and

\footnotetext{
How to cite this article: Chavan PD, Bhat VG, Poladia PP, Tiwari MR, Naresh C. Reduction in sample rejections at the preanalytical phase - Impact of training in a tertiary care oncology center. $\mathrm{J}$ Lab Physicians 2019;11:229-33.
} 
postanalytical. ${ }^{[2]}$ Due to advances in analytical systems and the introduction of quality control procedures such as internal quality control, external quality assurance programs, automation, and advances in electronic software systems, there is a considerable reduction in analytical errors. ${ }^{[3]}$ Preanalytical errors are reported to be $80 \%-93 \%{ }^{[4,5]}$ of the total errors encountered in diagnostic processes and are an important cause of repeat collections in patients. In a cancer hospital setting like ours, the major problem faced by the phlebotomist is difficulty in sample collection due to thrombosed veins postchemotherapy. One of the important tools in reducing the errors in the preanalytical phase is identification of problem areas and continuous training of the phlebotomy staff in appropriate collection techniques. ${ }^{[6,7]}$ Training is an important intervention aimed at reducing errors in any setting. What is also important is the extent of knowledge retained by the trainees posttraining and keeping the training process relevant for continuous improvement.

In this study, we looked at the efficacy of our training processes for staff to reduce preanalytical errors. The efficacy of the training process was evaluated annually with analysis of the rejection data vis-a-vis types of error and the respective wards/outpatient departments (OPDs) from where the errors occurred. Changes in the training modules were introduced with the aim to improve outcomes and were continually monitored.

\section{Materials and Methods}

This prospective study was conducted at the laboratory diagnostic services of a tertiary care oncology center with a hematopoietic stem cell transplant unit from 2012 to 2017. Our institute has a defined policy for sample rejection based on a list of criteria identified by the institute for rejection. We routinely determine the common causes of sample rejections, conduct a root cause analysis to identify the problem areas and undertake corrective action in the form of training of relevant staff to minimize errors. This analysis was broadly classified into two phases: the first phase comprised the period January to December 2012 and the second phase included the period from January 2013 to December 2017. During the first phase, we analyzed the problem areas, namely wards from where rejections were more common compared to others and also the common causes of sample rejection. There are seven wards in the hospital: bone marrow transplant where hematopoietic stem cell transplant patients are treated in the pre, post, and during transplant.

Hematolymphoid cancer ward deals with all hematolymphoid malignancies, surgical oncology wards deals with all pre- and postsurgery patients, medical oncology ward deals with all solid tumor patients, pediatric ward for children, intensive care unit (ICU), and daycare ward. Following a root-cause analysis, we decided to alter the current practices of training. Our practice included training sessions for the phlebotomy staff including nursing staff in the form of lectures once every year. To further reduce the errors, we decided to extend this training module for all the new nurses in their orientation sessions in addition to the annual training. The module was modified to include hands-on training for all the new nurses in the OPD sample collection area by the laboratory in-charge, in addition to the lectures on ideal preanalytical practices. We also started sharing the ward-wise analyzed data for sample rejection with the nurses during the training modules, helping the nurses better understand the problem areas for their wards and diligently act upon them. It also brought about a spirit of competition among the nurses to reduce the errors from their respective areas. The trainee pool consisted of mainly regular nursing staff; however, a part of the group was newly inducted nurses as and when required by the organization. The effects of these measures were seen during the period from January 2014 to December 2017. The assessment continued every year with the aim of reducing the errors.

\section{Results}

During the year 2012, a total of 48,889 samples were received in the laboratory for routine hematology and clinical chemistry analysis, of which 174 samples $(0.36 \%)$ were rejected. Following the interventions in the training module, the rejections started showing a decrease 2013 onward. In the year 2013, 58,822 samples were received and 113 samples $(0.19 \%)$ were rejected $(P<0.0001)$. During the period between 2014 and 2017, the sample rejection significantly decreased to $0.09 \%(P<0.0001)$ in $2014,0.09 \%(P=0.84)$ in $2015,0.05 \%(P=0.0004)$ in 2016 , and $0.05 \%(P=0.33)$ in 2017 [Table 1].

The ward-wise comparison of sample rejections showed surgical oncology ward, hematolymphoid cancer unit, and ICU as the areas contributing most to the sample rejection [Table 2].

However, rejections from all these wards reduced postintervention in the period between 2013 and 2017. The reduction was significant from surgical oncology ward $(P=0.01)$ and ICU $(P=0.0007)$ [Table 3].

The highest number of rejections in 2012 were for hemolyzed samples $(0.126 \%)$, followed by clotted samples (0.106), labeling errors $(0.073 \%)$, and samples contaminated by IV fluids $(0.012 \%)$. Over the period of 4 years from 2013 to 2017, the errors significantly reduced to $0.015 \%$ for hemolyzed samples ( $P=0.0001), 0.005 \%$ 
for contaminated samples, $0.036 \%$ for clotted samples, and $0.019 \%$ for labeling errors [Table 4 ].

\section{Discussion}

Errors in laboratory have been a major cause of concern, as laboratory results influence about $60 \%-70 \%$ of decisions made in the clinical setting. ${ }^{[8,9]}$ There have been considerable advances in the analytical part of the testing including equipment technology, automation, computer software, and implementation of quality control programs which have reduced the analytical errors to a great extent. ${ }^{[9-11]}$ However, in the preanalytical areas, majority of processes are still manual. A study by the American College of Pathologists observed that the most common reason for errors in the preanalytical setting is human error at about $82.6 \%$ and technical errors at only $4.3 \%{ }^{[12]}$ The challenge for the laboratories is to reduce these errors and deliver quality results. To achieve this, it is imperative to reduce the human part of errors which is possible through training of the

Table 1: Comparison of year-wise sample rejection

\begin{tabular}{|c|c|c|c|c|c|c|}
\hline & \multicolumn{6}{|c|}{ Years } \\
\hline & 2012 & 2013 & 2014 & 2015 & 2016 & 2017 \\
\hline $\begin{array}{l}\text { Number of samples } \\
\text { rejected }\end{array}$ & 174 & 113 & 66 & 76 & 43 & 57 \\
\hline $\begin{array}{l}\text { Total number of } \\
\text { samples received }\end{array}$ & 48,889 & 58,822 & 74,987 & 82,272 & $91,412 \subseteq$ & 97,548 \\
\hline $\begin{array}{l}\text { Percentage rejected } \\
\text { samples }\end{array}$ & 0.36 & 0.19 & 0.09 & 0.09 & 0.05 & 0.05 \\
\hline$P$ & & $<0.0001$ & $<0.0001$ & 0.84 & 0.0004 & 0.33 \\
\hline
\end{tabular}

individuals involved in the preanalytical processes. It is also important to evaluate the efficacy of these training methods and other corrective measures periodically to assess the subsequent improvement.

We did not assess the total laboratory errors from pre- to postanalytical processes in our setting. Our laboratory has a common sample accession area for hematology and clinical chemistry, so a common sample rejection record is maintained for all samples received for testing in both facilities. The net sample rejection rate in our laboratory was $0.36 \%$ in 2012 which is in agreement with various studies which have reported sample rejection rates in the range of $0.57 \%{ }^{[13]}-0.3 \% .^{[14]}$ One study by Gungor et al. has reported rejection rates of $1.4 \%$ for samples for complete blood count and $1.2 \%$ for clinical chemistry samples. ${ }^{[15]}$ Although we had a training program for staff responsible for blood sample collection, a review at the training program to reduce the errors was needed. After the training program was redesigned in 2013, the sample rejection rate in our study gradually dropped to $0.19 \%$ in $2013,0.09 \%$ in 2014 and 2015, and considerably to $0.05 \%$ in 2016 and 2017.

The most common reason for sample rejection in our study was hemolyzed samples, followed by clotted samples and labeling errors. This correlates with other studies like the ones by Goswami et al. ${ }^{[4]}$ and Lillo et al. ${ }^{[9]}$ who found hemolyzed samples to be the most common cause of sample rejections, usually the result of vigorous mixing of blood with the anticoagulants in the tube, forceful withdrawal, as well as dispensing of blood into

Table 2: Comparison of ward-wise sample rejection

\begin{tabular}{|c|c|c|c|c|c|c|c|c|}
\hline & $\begin{array}{c}\text { Hematolymphoid } \\
\text { cancer }\end{array}$ & BMT & Pediatrics & $\begin{array}{l}\text { Surgical } \\
\text { oncology }\end{array}$ & $\begin{array}{l}\text { Medical } \\
\text { oncology }\end{array}$ & ICU & Daycare & $\begin{array}{c}\text { Total samples } \\
\text { received }\end{array}$ \\
\hline 2012 & 31 & 8 & 7 & 58 & 16 & 43 & 9 & 48,889 \\
\hline Percentage rejections & 0.063 & 0.016 & 0.014 & 0.12 & 0.033 & 0.088 & 0.018 & \\
\hline 2013 & 19 & 4 & 5 & 32 & 5 & 43 & 5 & 58,822 \\
\hline Percentage rejections & 0.032 & 0.007 & 0.009 & 0.054 & 0.008 & 0.073 & 0.008 & \\
\hline 2014 & 25 & 3 & 0 & 7 & 0 & 22 & 9 & 74,987 \\
\hline Percentage rejections & 0.033 & 0.3004 & 0 & 0.0093 & 0 & 0.029 & 0.012 & \\
\hline 2015 & 5 & 1 & 1 & 12 & 0 & 50 & 7 & 82,272 \\
\hline Percentage rejections & 0.006 & 0.0012 & 0.0012 & 0.014 & 0 & 0.06 & 0.085 & \\
\hline 2016 & 6 & 3 & 0 & 15 & 4 & 15 & 0 & 91,412 \\
\hline Percentage rejections & 0.005 & 0.003 & 0 & 0.016 & 0.004 & 0.016 & 0 & \\
\hline 2017 & 9 & 5 & 0 & 14 & 14 & 12 & 3 & 97,548 \\
\hline Percentage rejections & 0.009 & 0.005 & 0 & 0.014 & 0.014 & 0.012 & 0.003 & \\
\hline
\end{tabular}

BMT=Bone marrow transplant, ICU=Intensive care unit

Table 3: Comparison of ward-wise sample rejection

\begin{tabular}{|c|c|c|c|c|c|c|c|c|}
\hline & $\begin{array}{c}\text { Hematolymphoid } \\
\text { cancer }\end{array}$ & BMT & Pediatrics & $\begin{array}{l}\text { Surgical } \\
\text { oncology }\end{array}$ & $\begin{array}{l}\text { Medical } \\
\text { oncology }\end{array}$ & ICU & Daycare & $\begin{array}{c}\text { Total samples } \\
\text { rejected }\end{array}$ \\
\hline 2012 & 31 & 8 & 7 & 58 & 16 & 43 & 9 & 174 \\
\hline 2013-2017 & 64 & 16 & 6 & 80 & 23 & 142 & 24 & 355 \\
\hline$P$ & 0.1 & 0.9 & 0.18 & 0.01 & 0.35 & 0.001 & 0.6 & \\
\hline
\end{tabular}

$\mathrm{BMT}=$ Bone marrow transplant, $\mathrm{ICU}=$ Intensive care unit 
Table 4: Comparison of rejection criteria

\begin{tabular}{|c|c|c|c|c|c|c|c|c|c|}
\hline $\begin{array}{l}\text { Rejection } \\
\text { criteria }\end{array}$ & $\begin{array}{c}\text { Labeling } \\
\text { errors }\end{array}$ & $\begin{array}{c}\text { Expired } \\
\text { vacutainer }\end{array}$ & $\begin{array}{l}\text { Specimen improperly } \\
\text { collected/suspected } \\
\text { of IV contamination }\end{array}$ & $\begin{array}{l}\text { Sample } \\
\text { hemolyzed/ } \\
\text { lipemic }\end{array}$ & $\begin{array}{l}\text { Quantity } \\
\text { not } \\
\text { sufficient }\end{array}$ & $\begin{array}{c}\text { Sample } \\
\text { partially/fully } \\
\text { clotted }\end{array}$ & $\begin{array}{l}\text { Soiled } \\
\text { requisition/ } \\
\text { outside of } \\
\text { container }\end{array}$ & $\begin{array}{c}\text { Sample } \\
\text { received without } \\
\text { requisition form }\end{array}$ & $\begin{array}{l}\text { Total } \\
\text { samples } \\
\text { received }\end{array}$ \\
\hline 2012 & 36 & 2 & 6 & 62 & 4 & 52 & 2 & 10 & 48,889 \\
\hline $\begin{array}{l}\text { Percentage } \\
\text { rejections }\end{array}$ & 0.073 & 0.004 & 0.012 & 0.126 & 0.008 & 0.106 & 0.004 & 0.02 & \\
\hline 2013 & 38 & 1 & 5 & 22 & 0 & 27 & 1 & 19 & 58,822 \\
\hline $\begin{array}{l}\text { Percentage } \\
\text { rejections }\end{array}$ & 0.064 & 0.003 & 0.008 & 0.037 & 0 & 0.045 & 0.003 & 0.032 & \\
\hline 2014 & 12 & 0 & 8 & 15 & 3 & 23 & 1 & 4 & 74,987 \\
\hline $\begin{array}{l}\text { Percentage } \\
\text { rejections }\end{array}$ & 0.016 & 0 & 0.01 & 0.02 & 0.004 & 0.03 & 0.001 & 0.005 & \\
\hline 2015 & 14 & 2 & 8 & 8 & 2 & 35 & 1 & 6 & 82,272 \\
\hline $\begin{array}{l}\text { Percentage } \\
\text { rejections }\end{array}$ & 0.017 & 0.002 & 0.009 & 0.009 & 0.002 & 0.042 & 0.001 & 0.006 & \\
\hline 2016 & 9 & 0 & 3 & 6 & 0 & 25 & 0 & 0 & 91,412 \\
\hline $\begin{array}{l}\text { Percentage } \\
\text { rejections }\end{array}$ & 0.009 & 0 & 0.003 & 0.006 & 0 & 0.027 & 0 & 0 & \\
\hline 2017 & 8 & 0 & 0 & 13 & 0 & 36 & 0 & 0 & 97,548 \\
\hline $\begin{array}{l}\text { Percentage } \\
\text { rejections }\end{array}$ & 0.008 & 0 & 0 & 0.013 & 0 & 0.036 & 0 & 0 & \\
\hline 2013-2017 & 81 & 3 & 24 & 64 & 5 & 146 & 3 & 29 & 405,041 \\
\hline $\begin{array}{l}\text { Percentage } \\
\text { rejections }\end{array}$ & 0.019 & 0.00007 & 0.005 & 0.015 & 0.001 & 0.036 & 0.00007 & 0.007 & \\
\hline$P$ & 0.66 & 0.73 & 0.18 & 0.0001 & 0.7 & 0.66 & 0.73 & 0.41 & \\
\hline
\end{tabular}

$\mathrm{IV}=$ Intravenous

collection tubes and blood collection through butterfly needles. ${ }^{[16]}$

Although clotted samples were the second most common cause of rejection in our study, it was the most common cause in other studies like the one by Guimarães et al. ${ }^{[13]}$ A probable cause for this is inadequate mixing of samples with anticoagulant. All the errors reduced considerably during the period 2013-2017, after the training program was redesigned.

Training is one of the mainstays of interventions required to reduce errors at preanalytical stage as shown in various studies. ${ }^{[6,7,9]}$ Posttraining the rate of errors reduced significantly in all these studies. Success of training programs depends on the transfer of the knowledge and skills learned by the trainees to their day-to-day activity. ${ }^{[17,18]}$ However, studies recording changes in performance of staff after the training have found that about $40 \%$ of benefits of the training are transferred by trainees to their jobs immediately. However, over a period of 6 months, this degree of transfer reduces to $25 \%$ and to $15 \%$ by the end of 1 year. ${ }^{[19]}$ To avoid this slump in productivity and repetition of errors, it is essential that retraining of the staff is conducted periodically.

There are broadly three factors that determine the extent of training transfer and improvements in the trainee posttraining: the training program and its design to transfer the knowledge, the efficacy of the trainee to absorb the training, and evaluation of the trainee posttraining to understand how much of the knowledge was transferred. ${ }^{[18]}$ Thus, for the success of any training program, it is essential to review the program design periodically and evaluate the trainees posttraining.

In our study, we decided to revise our training program with the view of brining some new learning objectives to improve the training outcomes. As Yang et al. suggested, we need to change the employee's behavior toward their job as success of training is dependent on it. ${ }^{[20]}$ One way to achieve this is to add activities in the training design that can bring about a change in the trainee's behavior. ${ }^{[21]}$ With this view, we decided to add the activities that could bring about this change. Our earlier training program included training lectures for the nurses and phlebotomists. Onsite practical training was given to the new staff and assessments were carried out. In the new module, in addition to lectures, the onsite training was also made mandatory for all the concerned staff. We also decided to share the results of the annual analysis of ward-wise sample rejection with the phlebotomists and nurses. Sharing of the results brought about a sense of competition among the staff which acted like a catalyst to bring about the needed change in their behavior toward the job. This was evident from the drop in sample rejection rates from wards which had high number of rejections. Rejections from surgical oncology ward reduced from 
$0.12 \%$ in 2012 to $0.014 \%$ in $2017(P=0.0107)$, from ICU from 0.088 in 2012 to 0.012 in $2017(P=0.0007)$, from medical oncology ward from $0.033 \%$ in 2012 to $0.014 \%$ in 2017, and from hematolymphoid cancer ward from $0.063 \%$ in 2012 to $0.009 \%$ in 2017 .

The process of quality assurance is a continuous activity in laboratory practice. Continual training of the staff and regular audits are the keys to reducing preanalytical errors. Our results also reinforce the fact that designing a training process with the aim of bringing about a change in the behavior of the trainee (behavior modification) as well as enhancing their skill set and periodical assessment of efficacy of these training processes are equally important in achieving the desired results for both the participant trainees and the organization. This, in turn, would result in reduction of errors, better implementation of good laboratory practice, and improved patient outcomes.

\section{Conclusion}

Common causes of sample rejection in our study were hemolyzed samples, clotted samples, followed by labeling errors which reduced considerably postintervention. Intervention in the form targeted training helps reduce errors and improves the quality of the results generated. Reviewing and redesigning the process of training periodically with the aim of achieving maximum improvement and transfer of knowledge in the trainees would contribute to better clinical outcomes.

\section{Financial support and sponsorship}

Nil.

\section{Conflicts of interest}

There are no conflicts of interest.

\section{References}

1. Sciacovelli L, Plebani M. The IFCC working group on laboratory errors and patient safety. Clin Chim Acta 2009;404:79-85.

2. Wiwanitkit V. Types and frequency of preanalytical mistakes in the first Thai ISO 9002:1994 certified clinical laboratory, a 6 - Month monitoring. BMC Clin Pathol 2001;1:5.

3. Sinici Lay I, Pınar A, Akbıyık F. Classification of reasons for rejection of biological specimens based on pre-preanalytical processes to identify quality indicators at a university hospital clinical laboratory in Turkey. Clin Biochem 2014;47:1002-5.

4. Goswami B, Singh B, Chawla R, Mallika V. Evaluation of errors in a clinical laboratory: A one-year experience. Clin Chem Lab Med 2010;48:63-6.

5. Nigam PK. Preanalytical errors: Some common errors in blood specimen collection for routine investigations in hospital patients. Clin Diagn Res 2011;5:659-61.

6. Bhat V, Tiwari M, Chavan P, Kelkar R. Analysis of laboratory sample rejections in the pre-analytical stage at an oncology center. Clin Chim Acta 2012;413:1203-6.

7. Romero A, Cobos A, Gómez J, Muñoz M. Role of training activities for the reduction of pre-analytical errors in laboratory samples from primary care. Clin Chim Acta 2012;413:166-9.

8. Forsman RW. Why is the laboratory an afterthought for managed care organizations? Clin Chem 1996;42:813-6.

9. Lillo R, Salinas M, Lopez-Garrigos M, Naranjo-Santana Y, Gutiérrez M, Marín MD, et al. Reducing preanalytical laboratory sample errors through educational and technological interventions. Clin Lab 2012;58:911-7.

10. Ashakiran S, Sumati ME, Murthy NK. A study of pre-analytical variables in clinical biochemistry laboratory. Clin Biochem 2011;44:944-5.

11. Najat D. Prevalence of pre-analytical errors in clinical chemistry diagnostic labs in Sulaimani city of Iraqi Kurdistan. PLoS One 2017;12:e0170211.

12. Valenstein P, Meier F. Outpatient order accuracy. A college of American pathologists Q-probes study of requisition order entry accuracy in 660 institutions. Arch Pathol Lab Med 1999;123:1145-50.

13. Guimarães AC, Wolfart M, Brisolara ML, Dani C. Causes of rejection of blood samples handled in the clinical laboratory of a university hospital in Porto Alegre. Clin Biochem 2012;45:123-6.

14. Dale JC, Novis DA. Outpatient phlebotomy success and reasons for specimen rejection. Arch Pathol Lab Med 2002;126:416-9.

15. Gungor M, Kural A, Seval H, BercikInal B, Coskun C, Ozturk H, et al. Measurement uncertainty in clinical biochemistry, ABSTRACTS. Clin Biochem 2009;42:324-37.

16. Carraro P, Servidio G, Plebani M. Hemolyzed specimens: A reason for rejection or a clinical challenge? Clin Chem 2000;46:306-7.

17. Diamantidis A, Chatzoglou P. Employee post-training behaviour and performance: Evaluating the results of the training process. Int J Train Dev 2014;18:149-70.

18. Cheng EW, Hampson I. Transfer of training: A review and new insights. Int J Manage Rev 2008;10:327-41.

19. Velada R, Caetano A, Michel JW, Lyons BD, Kavanagh MJ. The effects of training design, individual characteristics and work environment on transfer of training. Int J Train Dev 2007;11:282-94.

20. Yang H, Sanders K, Bumatay CP. Linking perception of training with organizational commitment: The moderating role of self-construals. Eur J Work Org Psychol 2012;21:125-49.

21. Burke A, Saks M. Accountability in training transfer: Adapting Schlenker's model of responsibility to a persistent but solvable problem. Hum Resour Dev Rev 2009;8:382-402. 